\title{
Resultados da Educação Superior: o ProUni em Foco ${ }^{1}$
}

\author{
Vera Lucia Felicetti \\ Alberto F. Cabrera
}

Resumo: Este artigo tem como cerne os resultados da formação na Educação Superior. Os participantes da pesquisa foram bolsistas e não bolsistas ProUni já egressos da Educação Superior de uma Instituição Comunitária do Sul do Brasil ingressantes nesse nível de ensino em 2005. Os objetivos pretenderam responder três questões da pesquisa: Qual a situação dos egressos ProUni e não ProUni no mercado de trabalho e como ela difere entre os dois grupos de graduados? Em que medida o ProUni motiva o egresso prounista a continuar estudando? Qual a satisfação dos egressos ProUni e não ProUni com aspectos relacionados à sua formação e ao seu trabalho e como ela difere entre os dois grupos de graduados? A metodologia usada teve cunho quantitativo e objetivo explicativo. Estatística descritiva e de inferência foram usadas na análise dos dados. Os resultados indicam o ProUni como tendo papel importante na formação da primeira geração de graduados. Também apontam que o ProUni coloca seus graduados no mesmo patamar de satisfação que seus colegas não ProUni no que diz respeito à formação, à realização de cursos após a graduação e à satisfação com fatores extrínsecos e intrínsecos referentes ao estar graduado, bem como à associação entre formação versus trabalho e a remuneração conquistada. Os resultados sinalizam a necessidade de pesquisas em âmbito nacional, envolvendo egressos da Educação Superior, bolsistas e não bolsistas.

Palavras-chave: Educação Superior. Resultados da Graduação. Egressos. ProUni.

\section{Outcomes of Higher Education: ProUni in Focus}

Abstract: This article has, as its core, the results of formation on Higher Education. Research participants were scholarship holders and non-scholarship holders ProUni already egresses of Higher Education from a South Brazil Non-profit Institution entering this level of education in 2005. The objectives sought to answer three research questions: What is the situation of egresses ProUni and not ProUni in the labor market, and how does it differ between the two groups of graduates? To what extent ProUni motivates prounist egress to go on studying? What is the satisfaction of ProUni and not ProUni graduate with aspects related to their formation and their work, and how does it differ between the two groups of graduates? The methodology used was of quantitative nature and explanatory goal. Descriptive and inferential statistics were used to analyze data. The results indicate ProUni as having an important role in the formation of the first generation of graduates. Also point out that ProUni places its graduates at the same level of satisfaction that his colleagues not ProUni with regard to formation, realization of courses after graduation and satisfaction with extrinsic and intrinsic factors related to being graduated, as well as the association between training versus job and earned salary. The results indicate the need for researches at a national level, involving graduates of Higher Education, both scholarship holders and not scholarship holders.

Key words: Higher Education. Graduation outcomes. Graduates. ProUni.

\footnotetext{
${ }^{1}$ Este artigo é resultado de um Projeto de Pesquisa financiado pelo Conselho Nacional de Desenvolvimento Científico e Tecnológico (CNPq) Chamada Pública MCTI/CNPq No 14/2013 / Universal.
} 


\section{Introdução}

Por muitos anos o acesso a Educação Superior no Brasil se deu via Vestibular (prova de ingresso) o qual foi criado em 1911 pela Lei 8.659 (BRASIL, 1911). O vestibular, por muitos anos, foi usado como a única forma de seleção para o ingresso em uma Instituição de Ensino Superior (IES), no qual eram aprovados os candidatos com maiores notas. Deste modo, os estudantes admitidos eram os melhor preparados, ou seja, aqueles que frequentavam as melhores escolas de Educação Básica e geralmente pertenciam a famílias com poder socioeconômico elevado, a chamada elite brasileira. Essas famílias ainda eram detentoras de um capital social e cultural, aspectos que contribuiam na aprovação no vestibular, diferentemente dos estudantes oriundos de escolas públicas e famílias sem capital cultural ou social.

A sociedade está organizada não apenas por bens econômicos, mas também pela produção de hábitos de classe, que são transmitidos principalmente pela família (BOURDIEU; PASSERON, 1964). No entanto, com o avançar dos anos, mudanças no cenário político e social brasileiro foram surgindo e novas formas de pensar e fazer em educação foram emergindo. O papel do vestibular, projetado para selecionar os "melhores" alunos, foi sendo questionado, e em alguns casos substituído por novas estratégias e formas de admissão.

Ganham força, nesse cenário, as políticas de ações afirmativas que são entendidas como "uma política pública que tenta reverter as políticas históricas de exclusão das mulheres e das minorias no ensino superior e de emprego" (CASHMORE, 2003, p. 31). Elas tentam universalizar a forma de acesso à Educação Superior. São estabelecidas, nesse ínterim, vagas na Educação Superior pública e privada via programas de governo. Entre eles, os de cotas para estudantes oriundos de grupos sub-representados (alunos egressos dos ensino público, afrodescendentes, indígenas, portadores de deficiência física e outros), ou, como apresentam Felicetti e Morosini (2009, p.2), grupos em desvantagens iniciais, que segundo as autoras correspondem àquelas que existem independentes do querer de cada um, tais como raça, sexo, idade, deficiências, família ou situação socioeconômica" (FELICETTI; MOROSINI, 2009, p. 12), em IES públicas e bolsas em IES privadas via o Programa Universidade para Todos ProUni.

Enunciado o título deste artigo, Resultados da Educação Superior: o ProUni em Foco, e alguns aspectos quanto ao acesso à Educação Superior no Brasil, entrarão em cena tanto os egressos da Educação Superior que foram bolsistas do Programa Universidade para Todos 
como aqueles que não foram, dando vez, assim, a aspectos relacionados aos resultados da formação universitária para ambos os grupos de graduados.

\section{Aporte Teórico}

O ProUni foi criado em 2004 e estabilizado pela Lei $\mathrm{N}^{0} 11.096$, de 13 de janeiro de 2005, sendo então um Programa do governo federal brasileiro, sob gestão do Ministério da Educação (MEC). Esse programa é destinado à concessão de bolsas ${ }^{2}$ de estudo em instituições privadas de Educação Superior com ou sem fins lucrativos, para brasileiros não portadores de diploma acadêmico. As bolsas podem ser integrais ou parciais (BRASIL, 2005).

Conforme o Art. $1^{\circ}, \S \S 1^{\circ}$ e $2^{\circ}$, da Lei 11.096 , a bolsa integral é concedida a brasileiros cuja renda familiar mensal per capita não exceda o valor de até 1 (um) salário-mínimo e 1/2 (meio). Para as parciais de $50 \%$ ou de $25 \%$, a renda familiar mensal per capita não deve exceder ao valor de até 3 (três) salários-mínimos, mediante critérios definidos pelo Ministério da Educação.

De acordo com o Artigo $2^{\circ}$ da mesma Lei $\mathrm{N}^{0}$ 11.096, a bolsa será destinada a estudante que tenha cursado o ensino médio completo em escola da rede pública, ou em instituições privadas na condição de bolsista integral; ao estudante portador de deficiência, nos termos da lei; ao professor da rede pública de ensino nos cursos de licenciatura, normal superior e pedagogia, destinados à formação do magistério da educação básica, independentemente da renda a que se referem os $\S \S 1^{\circ}$ e $2^{\underline{o}}$ do art. $1^{\circ} \underline{\text { desta Lei }}$ (BRASIL, 2005).

O ProUni, até o segundo semestre de 2014, havia ofertado 2.227 .038 bolsas de estudo, segundo dados apresentados pelo Sistema do ProUni, o Sisprouni (2015).

Muitos estudos comprovam a relevância do ProUni no que diz respeito ao acesso à Educação Superior (SILVA, 2006; LIMA, 2007; REIS, 2008; CARVALHO, 2011; FELDMAN, 2010; BORGHI, 2013; FELICETTI, 2014a, 2014b; BOVERIO, 2014). Alguns apontam a não atenção dada pelo Programa para a permanência dos bolsistas na universidade (RODRIGUES, 2008; OLIVEIRA, 2012; SILVA, 2011; BORGHI, 2013). Outros trazem sérias críticas ao Programa, tais como ser uma forma de o governo reduzir os investimentos em IES públicas em detrimento das privadas (ALMEIDA, 2006; BENITEZ, 2007), ou então a não realização de melhorias na Educação Básica pública, o que, segundo Mello (2007), se

\footnotetext{
${ }^{2}$ Bolsa de estudo refere-se às semestralidades ou anuidades escolares fixadas com base na Lei $n^{\circ} 9.870$, de 23 de novembro de 1999.
} 
fosse feito, colocaria os alunos egressos da educação pública no mesmo patamar de competição que seus pares oriundos de instituições privadas. Também há autores que dizem que o Programa não atinge todas as regiões da mesma maneira (LIMA, 2007).

Estes estudos têm diferentes sujeitos participantes nas pesquisas, entre eles bolsistas do Programa enquanto alunos (MONGIM, 2010; PEREIRA FILHO, 2011); gestores (KRAMES, 2010); professores (RODRIGUES, 2008), e há ainda os de cunho documental (OLIVEIRA, 2007; GONÇALVES DE SOUSA, 2008; ROCHA, 2009; MARINELLI, 2010; CARVALHO, 2011). Outros com egressos ProUni (FELICETTI, 2011, 2012, 2014a, 2014b; COSTA, 2012; OLIVEIRA, 2012), ou envolvendo egressos e bolsistas, mas sem compará-los como o estudo de Bovério (2014), e ainda aqueles que fazem pequenas comparações entre aluno bolsista e não bolsista no âmbito acadêmico, como o trabalho de Mongim (2010).

Estudos envolvendo egressos bolsistas ProUni ou não bolsistas são ainda incipientes, o que denota a necessidade de estudos voltados a esse universo. Nesta direção, o Sistema Nacional de Avaliação da Educação Superior - SINAES mostra, em seu documento, a necessidade de "políticas de acompanhamento do egresso e a programas de educação continuada, voltados para o egresso.” (SINAES, 2009, p. 181).

Pesquisas com egressos são usadas para diferentes objetivos, entre eles, proporcionar melhor planejamento acadêmico e orçamentário, reorganização de metas, identificação de problemas e ainda verificar a necessidade do mercado de trabalho (EWELL, 1986, 2005). Assim, ouvir e acompanhar os egressos possibilita identificar como está sendo o retorno do investimento por eles realizado em um curso superior, em destaque aqui, o investimento realizado pelo governo federal via Programa Universidade para Todos.

No Brasil, estudos tendo egressos da Educação Superior como cernes de investigação são recentes (ULIANA, 2011; SILVA, 2012; PITA, 2011; COELHO, 2011; FERNANDES, 2011), bem como os que envolvem egressos ProUni (FELICETTI, 2011, 2012, 2014a, 2014b; COSTA, 2012; ANDRIOLA, 2014; GERALDO, 2010; SOUZA, 2011; BOVERIO, 2014), sendo um bom número deles fruto de teses e dissertações. No entanto, estudos comparativos envolvendo egressos ProUni e não ProUni são ainda incipientes no cenário brasileiro.

Investigar como estão os egressos desse Programa, bem como seus pares após a graduação, permite saber acerca da satisfação com a formação e com o trabalho conquistado, representando medidas diretas de avaliação do desempenho do ProUni, sinalizando desse modo a eficácia ou não do Programa. Somente se pode avaliar se um programa está realizando mudanças na sociedade analisando-o como um todo, ou seja, estudando ambos os grupos de egressos, os que foram bolsistas ProUni e os que não foram. 
Assim, diante da tríade Educação Superior, resultados da formação e ProUni, este artigo apresenta os achados da terceira ${ }^{3}$ parte das análises realizadas junto ao banco de dados proveniente das respostas de egressos da Educação Superior, ProUni e não ProUni, que ingressaram em uma IES Comunitária do Rio Grande do Sul em 2005.

\section{Metodologia}

A metodologia usada neste estudo foi de cunho quantitativo, com objetivo explicativo. Tal opção é justificável devido ao escopo das questões investigativas delineadas neste estudo, ou seja, o propulsor, em um estudo, é o problema de pesquisa e a este está diretamente associada a abordagem metodológica a ser usada (ASTI VERA, 1979).

O uso da quantificação na coleta e no tratamento das informações, com o uso de técnicas estatísticas, proporciona resultados com margens maiores de segurança, evitando distorções de análises e interpretações, uma vez que análises estatísticas podem explicar o grau de relação ou correlação e o modo como determinadas variáveis estão operando (DIEHL, 2004). Neste caso, as variáveis estão relacionadas a aspectos de satisfação após a graduação e situação sociodemográfica dos egressos ProUni e não ProUni de uma Instituição Comunitária de Educação Superior do Sul do Brasil que ingressaram neste nível de ensino em 2005 e estavam graduados em junho de 2014. Deste modo, este estudo possui também uma abordagem comparativa, pois analisa as variáveis comparando-as entre egressos que tiveram a bolsa ProUni e os que não a tiveram, descrevendo e explicando as diferenças e semelhanças existentes entre os grupos.

Para tanto as questões norteadores deste estudo foram:

- Qual a situação dos egressos ProUni e não ProUni no mercado de trabalho, e como ela difere entre os dois grupos de graduados?

- Em que medida o ProUni motiva o egresso prounista a continuar estudando?

- Qual a satisfação dos egressos ProUni e não ProUni nos aspectos relacionados à sua formação e ao seu trabalho, e como ela difere entre os dois grupos de graduados?

Como já mencionado anteriormente, os sujeitos desta pesquisa são egressos de uma Instituição de Educação Superior Comunitária do Rio Grande do Sul - Brasil que ingressaram em diferentes cursos de graduação ${ }^{4}$ da Instituição em 2005. O total de ingressantes foi de

\footnotetext{
${ }^{3}$ Este artigo corresponde a terceira parte da análise realizada com os dados do projeto intitulado Bolsistas ProUni e não ProUni ingressantes no Ensino Superior em 2005 em uma IES: onde e como estão os egressos?

${ }^{4}$ Cursos de não licenciatura: Administração, Agronomia, Arquitetura e Urbanismo, Ciências Sociais, Ciências Contábeis, Comunicação Social, Direito, Enfermagem, Engenharia Civil, Farmácia, Fisioterapia, Informática, Medicina Veterinária, Nutrição, Psicologia, Sistema de Informação, Transações Imobiliárias. Cursos de licenciatura: Ciências Biológicas, Artes Plásticas, Artes Visuais, Educação Física, História, Letras, Matemática, P.F.P.S. (Programa de Formação de Professores em Serviço), Pedagogia.
} 
3.967 alunos. Destes, 1.473 (37,13\%) estavam graduados em junho de 2014, quando esta pesquisa teve início.

A Instituição participante da pesquisa forneceu as informações acerca do endereço de contato dos egressos, tais com e-mails e telefones. Todos os critérios éticos de sigilo e respeito aos participantes foram adotados. Dos 1.473 endereços fornecidos, o montante de 822 $(55,8 \%)$ era inválido, ou seja, telefones ou e-mails inválidos ou sem telefone ou e-mail, restando $651(44,2 \%)$ possíveis participantes, visto que estes tinham e-mail ou telefone válidos. Dos 651, 186 (28,57\%) não tinha registro de e-mail na IES, então eles foram contatados inicialmente por telefone e convidados a responder o instrumento de pesquisa via $e$-mail. Setenta e cinco $(40,32 \%)$ dos contatados inicialmente por telefone forneceram seus $e$ mails e responderam ao instrumento. Dos 465 (71,43\%) que tinham e-mail válido fornecido pela IES, somente $122(26,24 \%)$ responderam ao questionário de pesquisa, mesmo tendo sido realizadas cinco tentativas. Por fim, obteve-se o total de 197 questionários respondidos, correspondendo a 30,28\% dos 651 contatados. Essa média está acima da esperada de respostas para questionários enviados via correio eletrônico, a qual está em torno de $25 \%$ (MARCONI; LAKATOS, 2003). O procedimento de ligações telefônicas e (re)envio de $e$ mails ocorreu de agosto de 2014 a março de 2015.

O questionário de pesquisa foi gerado no programa Google Docs que fornece um link para cada instrumento gerado. Foi gerado um link para cada possível respondente, o qual foi associado a um código enviado aos egressos

As questões que caracterizaram os aspectos relacionados aos resultados da formação envolveram sexo, idade ${ }^{5}$, ser o primeiro membro da família a se graduar na Educação Superior, ter aumento salarial após graduar-se, trabalho estar relacionado com a formação, fazer o mesmo curso caso pudessem começar novamente, se estavam realizando algum curso de formação continuada, quem estava trabalhando e se o seu trabalho era relacionado com a sua graduação, a quantidade de horas semanais trabalhadas, a categoria administrativa, o tipo de vínculo empregatício e o salário atual dos graduados. A questão se faria o mesmo curso caso pudesse começar novamente tinha respostas na escala likert, envolvendo grau de concordância, que variaram de "discordo totalmente", "discordo parcialmente", "nem concordo nem discordo", "concordo parcialmente" e "concordo totalmente". Os participantes também foram questionados nos aspectos relacionados à satisfação, tais como: satisfação com o trabalho e com o respectivo salário, com as práticas, teorias e métodos de ensino

\footnotetext{
${ }^{5}$ Idade correspondente ao ingresso na IES em 2005.
} 
desenvolvidos pelos docentes, com as atividades extracurriculares oferecidas pela instituição, com a formação conquistada, com as competências desenvolvidas, com os conhecimentos adquiridos e com as possibilidades de crescimento profissional. A estas questões foram atribuídos valores conforme as opções de formatos de respostas na Escala Likert, envolvendo o grau de satisfação que varia de 1 a 5 , sendo totalmente insatisfeito igual a 1; parcialmente satisfeito igual a 2; nem satisfeito nem insatisfeito 3; parcialmente satisfeito valendo 4 e totalmente satisfeito com valor 5. Estas atribuições foram necessárias para poder calcular a média e o desvio padrão quando necessário. Assim, somou-se média máxima 5 em cada grupo de análise considerado.

A análise foi dividida em duas partes, a saber: a primeira envolvendo os 197 respondentes e a segunda parte contemplando somente os egressos que não estavam desempregados, ou seja, 179.

Os questionários respondidos geraram links individuais, pois cada um teve seu próprio link. Sendo assim, as respostas foram exportadas e organizadas inicialmente na planilha Excel que posteriormente foi importada pelo Stata/IC13.1 - Statistics/Data Analysis, através do qual realizou-se análises estatísticas e de inferência pertinentes a este estudo (ACOCK, 2014).

Foi calculado o $\chi^{2}$ (qui-quadrado) para testar a associação entre ser ou não ser ProUni e os níveis das variáveis constantes no instrumento de pesquisa. A chance dos egressos ProUni terem sido os primeiros da família a graduarem-se na Educação Superior foi calculada pela razão de chance. Para as questões que envolveram aspectos relacionados à satisfação, foi examinada a relativa contribuição de cada componente (cada questão), através da análise fatorial que agrupa as variáveis latentes conforme o grau de consistência interna. Posteriormente, o grau de confiabilidade da consistência interna de cada componente foi classificado de acordo com as 5 escalas do Alpha de Cronbach, assim distribuídas: muito baixa $(\alpha \leq 0,30)$, baixa $(0,30<\alpha \leq 0,60)$, moderada $(0,60<\alpha \leq 0,75)$, alta $(0.75<\alpha \leq 0,90)$ e muito alta $(\alpha>0,90)($ CRONBACH; SHAVELSON, 2004). O T-test foi usado, após a identificação dos fatores, para testar as possíveis diferenças nas médias dos mesmos entre os dois grupos ProUni e não ProUni. Os níveis de significância menores que 5\% $(\mathrm{p}<0,05)$ foram considerados significativos, e entre $5 \%$ e $10 \%(0,05$ e 0,1$)$ considerados como indicativos de significância de acordo com Bós (2012). As análises compararam egressos que foram bolsistas ProUni com os que não foram. 


\section{Análise e Discussão}

A maioria dos ingressantes, tanto no grupo dos que foram bolsistas ProUni como no dos que não foram, corresponde ao sexo feminino. No grupo de não ProUni o percentual foi de 57,14\% (80), e entre os ProUni o percentual foi maior, com 63,10\% (36). Não houve relação estatisticamente significativa para o sexo entre ser ProUni ou não, com p=0,437.

Com relação à idade, a maioria dos egressos tinha idade menor que 25 anos quando do ingresso na universidade em ambos os grupos, correspondendo a 61,43\% (86) aos não ProUni e $84,21 \%$ (48) aos ProUni. Em extensão, o percentual total foi de 68,02\% (134) para idade menor que 25 anos. Houve relação estatisticamente significativa entre a idade de acesso e os grupos de graduados, com $\mathrm{p}=0,003$, significando que o ProUni proporcionou, na instituição estudada, o acesso à Educação Superior a um grupo de alunos com idade menor de 25 anos.

$\mathrm{Na}$ Tabela 1 constam os dados referentes a ser ou não o primeiro membro da família a graduar-se na Educação Superior entre os egressos ProUni e não ProUni. Foi considerado como definição de primeira geração a ter o título de Educação Superior aqueles estudantes que correspondem ao primeiro membro da família entre os irmãos e os pais, sendo essa definição apoiada por diversos autores (TERENZINI et al., 1996; CHOY et al., 2000; RODRIGUEZ, 2003; ISHITANI, 2006).

Tabela 1 - Ser o primeiro da família a graduar-se entre os graduados ProUni e não ProUni

\begin{tabular}{|c|c|c|c|c|}
\hline Variável & Fatores & $\begin{array}{l}\text { Não ProUni } \\
\operatorname{Fr}(\%)\end{array}$ & $\begin{array}{l}\text { ProUni } \\
\text { Fr(\%) }\end{array}$ & $\begin{array}{l}\text { Total } \\
\text { Fr(\%) }\end{array}$ \\
\hline \multirow{2}{*}{$\begin{array}{l}\text { Primeiro a } \\
\text { graduar-se }\end{array}$} & Sim & $79(56,43)$ & $43(75,44)$ & $122(61,93)$ \\
\hline & Não & $61(43,57)$ & $14(24,56)$ & $75(38,07)$ \\
\hline \multicolumn{2}{|c|}{ Total } & $140(100)$ & $57(100)$ & $197(100)$ \\
\hline
\end{tabular}

Fonte: Banco de dados formado pelas respostas dos questionários. $\mathrm{p}=0,013$

É possível observar que a maioria dos respondentes indicou serem aos primeiros membros da família a graduarem-se, tanto entre os que foram ProUni como entre os que não foram. Entre os não ProUni, o percentual foi de 56,43\% (79) e entre os ProUni foi de 75,44\% (43). Houve relação estatisticamente significativa entre os grupos de egressos e a variável primeiro a graduar-se na Educação Superior, com $p=0,013$. Os egressos ProUni apresentaram uma razão de chance de 2,37, em relação aos não ProUni, quanto à chance de terem sido os primeiros da família a graduarem-se. Isto significa que os egressos ProUni têm uma maior 
chance de serem os primeiros membros da família a graduarem-se na Educação Superior que seus colegas não ProUni. No Brasil, estudos envolvendo estudantes ou egressos de primeira geração ainda são incipientes. Alguns apenas mencionam os participantes como sendo de primeira geração e não os tendo como cernes de investigações (MONGIM, 2010; ROCHA, 2008; FELICETTI, 2011). Nesta direção, há evidências da necessidade de estudos envolvendo esse perfil estudantil. Pascarella e Terenzini (1991) apontam, em suas pesquisas, realizadas ainda na década de 90 nos Estados Unidos, a importância da realização de pesquisas sobre as mudanças ocorridas dentro da faculdade, devido ao novo perfil de estudantes nela ingressantes, entre eles os de primeira geração.

Com relação à questão que indagava sobre a possibilidade de começar novamente a faculdade, e se eles fariam o mesmo curso, observa-se, na Tabela 2, que entre os não ProUni o maior percentual está para as opções provavelmente sim e definitivamente sim, com o percentual de 30,0\% (42) em ambas as respostas. Já entre os que foram bolsistas, o maior percentual está para provavelmente sim com 31,58\% (18), seguido por 28,07\% (16) com a opção provavelmente não. Destaca-se aqui que, embora a maioria, 58,38\% (115), tenha respondido no âmbito do sim, tem-se 33,5\% (66) que optaram pelas opções envolvendo não. Não houve associação estatisticamente significante entre ter sido ProUni ou não e a escolha do curso, p=0,607. Embora não tenha havido relação estatisticamente significante, pode-se observar que a maioria $(58,38 \%)$ das respostas está no âmbito da satisfação com o curso realizado, quer seja entre os prounistas ou entre seus colegas. Os estudos de Felicetti (2011, 2012, 2014a) e Souza (2011) envolvendo egressos ProUni apontam altos índices de satisfação com a realização do curso superior.

Tabela 2 - Fazer o mesmo curso se pudesse começar de novo

\begin{tabular}{|c|c|c|c|c|}
\hline Começar de novo & $\begin{array}{l}\text { Não ProUni } \\
\text { Fr. (\%) }\end{array}$ & $\begin{array}{l}\text { ProUni } \\
\text { Fr. (\%) }\end{array}$ & $\begin{array}{l}\text { Total } \\
\text { Fr. (\%) }\end{array}$ & Fr. (\%) \\
\hline Definitivamente não & $13(9,29)$ & $7(12,28)$ & $20(10,15)(A)$ & $(A+B)$ \\
\hline Provavelmente não & $30(21,43)$ & $16(28,07)$ & $46(23,35)(\mathrm{B})$ & $=66(33,5)$ \\
\hline Sem opinião & $13(9,29)$ & $3(5,26)$ & $16(8,12)$ & \\
\hline Provavelmente sim & $42(30,0)$ & $18(31,58)$ & $60(30,46)(C)$ & $(\mathrm{C}+\mathrm{D})$ \\
\hline Definitivamente sim & $42(30,0)$ & $13(22,81)$ & $55(27,92)(D)$ & $=115(58,38)$ \\
\hline Total & $140(100)$ & $57(100)$ & $197(100)$ & \\
\hline
\end{tabular}

Fonte: Banco de dados formado pelas respostas dos questionários. $\mathrm{P}=0,607$ 
Na Tabela 3 constam os percentuais referentes à realização de algum curso após a graduação. Observa-se, em ambos os grupos, que o maior percentual de respostas está na realização de cursos de especialização não na área de formação, com $40 \%$ (56) entre os não ProUni e 33,33\% (19) entre os ProUni. O segundo maior percentual foi para a não realização de cursos, também para os dois grupos, com 30,71\% (43) para os não ProUni e 21,05\% (12) entre os ProUni. Houve associação estatisticamente significativa, com p=0,013 entre ser ProUni e não ProUni e a realização de cursos após a faculdade. Destaca-se aqui o percentual de 19,30\% (11) entre os egressos ProUni que encontram-se realizando outra faculdade, sendo esse maior que o percentual de egressos não ProUni, que foi de somente 3,57\%. Acerca dos 11 prounistas que estavam realizando outro curso de graduação, foi identificado que os mesmos responderam com positivamente sim às questões relacionadas à satisfação com a graduação completada e com o trabalho atual.

Tabela 3 - Fez ou está fazendo algum curso após o término da graduação entre os egressos

\begin{tabular}{lccc}
\hline \multicolumn{1}{c}{ Fez ou está fazendo } & Não ProUni & ProUni & Total \\
& Fr. (\%) & Fr. (\%) & (\%)(27,92) \\
\hline Não fiz e nem estou fazendo & $43(30,71)$ & $12(21,05)$ & $12(6,09)$ \\
Curso de língua estrangeira & $9(6,43)$ & $3(5,26)$ & $21(10,66)$ \\
Pós-graduação Stricto Sensu & $14(10,0)$ & $7(12,28)$ & $18(9,14)$ \\
Especialização na área & $13(9,29)$ & $5(8,77)$ & $\mathbf{7 5 ( 3 8 , 0 7 )}$ \\
Especialização não na área & $56(40,0)$ & $19(33,33)$ & $16(8,12)$ \\
Outra graduação & $5(3,57)$ & $11(19,30)$ & $\mathbf{1 9 7 ( 1 0 0 )}$ \\
\hline \multicolumn{1}{c}{ Total } & $\mathbf{1 4 0 ( 1 0 0 )}$ & $\mathbf{5 7 ( 1 0 0 )}$ &
\end{tabular}

Fonte: Banco de dados formado pelas respostas dos questionários. P=0,013

Tais dados parecem indicar o desenvolvimento do gosto pelo estudar, isto é, o desenvolvimento de um capital cultural por um perfil da população que sem a bolsa não teria tido condições de realizar estudos de nível superior. Isto representa um novo grupo de pessoas aptas a entrar no que Bourdieu e Passeron (1964) chamaram de "classes cultivadas", possuidoras de um "tesouro" que é a experiência a ser transmitida pela família aos seus filhos. Classes essas que são detentoras do gosto, do estilo e do espírito da escolaridade, o qual começa a ser desenvolvido entre um novo grupo da população brasileira. Portanto, pessoas oriundas grupos em desvantagens iniciais passam a se beneficiar da cultura escolar e, em extensão, isso pode ser desenvolvido entre seus descendentes, uma vez que passam a aprender a jogar as regras do jogo dos mais socialmente educados. 
Observam-se, na Tabela 4, dados referentes ao aumento salarial ou não depois da graduação. A maioria dos egressos, tanto no grupo dos que não foram bolsistas como no dos que foram, teve aumento salarial. Entre os não bolsistas, 67,14\% (94) tiveram aumento, e entre os bolsistas o percentual foi maior, com 77,19\% (44). O percentual total de egressos que não estava trabalhando quando responderam ao instrumento de pesquisa aqui proposto correspondeu a $9,14 \%(18)$.

Tabela 4 - Teve aumento ou não no nível salarial após a graduação

\begin{tabular}{cccc}
\hline & $\begin{array}{c}\text { Não ProUni } \\
\text { Fr. (\%) }\end{array}$ & $\begin{array}{c}\text { ProUni } \\
\text { Fr. (\%) }\end{array}$ & $\begin{array}{c}\text { Total } \\
\text { Fr. (\%) }\end{array}$ \\
\hline Não trabalha & $15(10,71)$ & $3(5,26)$ & $18(9,14)$ \\
Sem aumento salarial & $31(22,14)$ & $10(17,54)$ & $41(20,81)$ \\
Com aumento salarial & $94(67,14)$ & $44(77,19)$ & $138(70,05)$ \\
\hline Total & $\mathbf{1 4 0 ( 1 0 0 )}$ & $\mathbf{5 7 ( 1 0 0 )}$ & $\mathbf{1 9 7 ( 1 0 0 )}$ \\
\hline
\end{tabular}

Fonte: Banco de dados formado pelas respostas dos questionários. $\mathrm{P}=0,315$

Não houve associação estatisticamente significante, $p=0,315$, entre os dois grupos e ter aumento salarial ou não, o que demonstra que a formação em nível superior parece oferecer as mesmas oportunidades de conquista salarial após graduados. Os estudos de Costa (2012) também indicam que houve aumento salarial após a graduação para egressos ProUni.

As análises que seguem, nas Tabelas 5, 6, 7, 8 e 9, foram realizadas envolvendo somente os egressos que estavam trabalhando quando da realização da pesquisa, cujo total correspondeu a 179 , ou seja, $90,86 \%$ do total de respondentes.

Na Tabela 5 constam os percentuais referentes ao grau de concordância de o trabalho estar relacionado com a formação acadêmica ou não. A maioria dos egressos, em ambos os grupos, encontra-se trabalhando na área de formação, ou seja, 51,20\% (64) entre os não ProUni e 55,56\% (30) entre os ProUni. Não houve associação estatisticamente significativa entre ser bolsista ou não e o trabalho estar relacionado com a formação acadêmica, $p=0,505$. Costa (2012) e Felicetti (2012, 2014b) identificam, em seus estudos com egressos ProUni, que a maioria deles encontrava-se atuando na área de formação. 
Tabela 5 - Trabalho relacionado com a formação dos graduados ProUni e não ProUni

\begin{tabular}{|c|c|c|c|}
\hline & $\begin{array}{c}\text { Não ProUni } \\
\text { Fr. (\%) }\end{array}$ & $\begin{array}{l}\text { ProUni } \\
\text { Fr. (\%) }\end{array}$ & $\begin{array}{c}\text { Total } \\
\text { Fr. (\%) }\end{array}$ \\
\hline Discordo totalmente & $21(16,80)$ & $13(24,07)$ & $34(18,99)$ \\
\hline Discordo parcialmente & $6(4,80)$ & $1(1,85)$ & $7(3,91)$ \\
\hline Nem concordo nem discordo & $9(7,20)$ & $2(3,70)$ & $11(6,15)$ \\
\hline Concordo parcialmente & $25(20,0)$ & $8(14,81)$ & $33(18,44)$ \\
\hline Concordo totalmente & $64(51,20)$ & $30(55,56)$ & $94(52,51)$ \\
\hline Total & $125(100)$ & $54(100)$ & $179(100)$ \\
\hline
\end{tabular}

Fonte: Banco de dados formado pelas respostas dos questionários. $\mathrm{P}=0,505$

Com relação às horas trabalhadas, Tabela 6 , é possível ver que a maioria dos egressos, em ambos os grupos, trabalha 40 horas ou mais, e menos de 60 horas semanais, perfazendo um total geral de 57,54\% (103) dos 179 respondentes. Não houve associação estatisticamente significante entre os dois grupos de egressos e as horas trabalhadas semanalmente, $p=0,858$.

Tabela 6 - Horas semanais trabalhadas pelos graduados ProUni e não ProUni

\begin{tabular}{cccc}
\hline & $\begin{array}{c}\text { Não ProUni } \\
\text { Fr. (\%) }\end{array}$ & $\begin{array}{c}\text { ProUni } \\
\text { Fr. (\%) }\end{array}$ & $\begin{array}{c}\text { Total } \\
\text { Fr. (\%) }\end{array}$ \\
\hline $\begin{array}{c}\text { Menos de 20 horas } \\
20 \text { horas ou mais e } \\
\text { menos de 40 horas }\end{array}$ & $1(0,80)$ & $1(1,85)$ & $2(1,12)$ \\
$\begin{array}{l}40 \text { horas ou mais e } \\
\text { menos de 60 horas } \\
60 \text { horas ou mais }\end{array}$ & $36(28,80)$ & $17(31,48)$ & $53(29,61)$ \\
\hline Total & $74(59,20)$ & $29(53,70)$ & $103(57,54)$ \\
\hline
\end{tabular}

Fonte: Banco de dados formado pelas respostas dos questionários. $\mathrm{P}=0,858$

As categorias administrativas de maior carga horária de trabalho dos egressos podem ser observadas na Tabela 7. Nela é possível ver que, entre os egressos não ProUni, a maioria $55,20 \%$ (69) trabalha no setor público, seguido do privado com 31,20\% (39) e autônomo com $13,60 \%$ (17). Entre os que foram bolsistas ProUni, o maior percentual também está no setor público, embora com menor frequência, com 48,15\% (26), seguido pelo privado com 35,19\% (19) e autônomo com 16,67\% (9). Não houve associação estatisticamente significante entre os dois grupos de egressos e a categoria administrativa em que se encontram, $p=0,676$. 
Tabela 7 - Categoria administrativa do trabalho dos graduados ProUni e não ProUni

\begin{tabular}{cccc}
\hline & $\begin{array}{c}\text { Não ProUni } \\
\text { Fr. (\%) }\end{array}$ & $\begin{array}{c}\text { ProUni } \\
\text { Fr. (\%) }\end{array}$ & $\begin{array}{c}\text { Total } \\
\text { Fr. (\%) }\end{array}$ \\
\hline Autônomo & $17(13,60)$ & $9(16,67)$ & $26(14,53)$ \\
Público & $69(55,20)$ & $26(48,15)$ & $95(53,07)$ \\
Privado & $39(31,20)$ & $19(35,19)$ & $58(32,40)$ \\
\hline Total & $\mathbf{1 2 5 ( 1 0 0 )}$ & $\mathbf{5 4 ( 1 0 0 )}$ & $\mathbf{1 7 9 ( 1 0 0 )}$ \\
\hline
\end{tabular}

Fonte: Banco de dados formado pelas respostas dos questionários. P=0,676.

O vínculo empregatício dos egressos pode ser verificado na Tabela 8. Observa-se que entre os não bolsistas o maior percentual é de 41,60\% (52), correspondendo aos concursados. Já entre os bolsistas, o maior percentual é de contratados, o qual corresponde a 48,15\% (26). Em ambos os grupos, o menor percentual está para os que são autônomos e têm algum outro vínculo de menor carga horária. Não houve associação estatisticamente significante entre o vínculo empregatício e os dois grupos de egressos, p=0,268. Essa diferença, embora não significativa, pode estar relacionada ao fato da idade dos não bolsistas ser maior, tendo tido mais oportunidades de serem aprovados em concurso público.

Tabela 8 - Vínculo empregatício dos graduados ProUni e não ProUni

\begin{tabular}{cccc}
\hline & Não ProUni & ProUni & Total \\
& Fr. (\%) & Fr. (\%) & Fr. (\%) \\
\hline Autônomo e outro & $27(21,60)$ & $12(22,22)$ & 39(21,79) \\
Contratado & $46(36,80)$ & $26(48,15)$ & $68(37,99)$ \\
Concursado & $52(41,60)$ & $16(29,63)$ & $\mathbf{1 7 9}(\mathbf{1 0 0})$ \\
\hline Total & $\mathbf{1 2 5 ( 1 0 0 )}$ & $\mathbf{5 4 ( 1 0 0 )}$ &
\end{tabular}

Fonte: Banco de dados formado pelas respostas dos questionários. $\mathrm{P}=0,268$

O salário atual dos egressos pode ser visto na Tabela 9. Observa-se que o menor percentual está para o salário mensal de até um salário mínimo e meio por mês, em ambos os grupos de egressos. Já o maior percentual é diferente entre os dois grupos de egressos. Para os que não foram bolsistas, o maior percentual está para a renda superior a quatro salários mínimos mensais, com 32,80\% (41). Entre os que foram prounistas, o maior percentual está para o salário superior a um salário mínimo e meio até três salários mensais, com 37,04\% (20). Não houve associação estatisticamente significante entre o salário mensal e os dois grupos de egressos, $p=0,513$. Embora os que não foram bolsistas do ProUni tenham um percentual maior, com salário acima de quatro salários mínimos mensais, isso não representa 
uma diferença capaz de justificar que os não bolsistas tenham melhores salários que seus colegas que foram bolsistas, ou seja, ambos os grupos, quando colocados no mercado de trabalho, parecem ter condições salariais semelhantes, o que coloca ambos os grupos na mesma condição de conquista salarial.

Tabela 9 - Salário atual dos graduados ProUni e não ProUni

\begin{tabular}{|c|c|c|c|}
\hline & $\begin{array}{c}\text { Não ProUni } \\
\text { Fr. (\%) }\end{array}$ & $\begin{array}{l}\text { ProUni } \\
\text { Fr. (\%) }\end{array}$ & $\begin{array}{c}\text { Total } \\
\text { Fr. (\%) }\end{array}$ \\
\hline Até um salário mínimo e meio & $22(17,60)$ & $10(18,52)$ & $32(17,88)$ \\
\hline $\begin{array}{l}\text { Mais de } 1 \text { salário mínimo } \\
\text { e meio até } 3 \text { salários }\end{array}$ & $36(28,80)$ & $20(37,04)$ & $56(31,28)$ \\
\hline $\begin{array}{l}\text { Mais de } 3 \text { salários mínimos } \\
\text { até } 4 \text { salários mínimos e meio }\end{array}$ & $26(20,80)$ & $12(22,22)$ & $38(21,23)$ \\
\hline Mais de 4 salários mínimos & $41(32,80)$ & $12(22,22)$ & $53(29,61)$ \\
\hline Total & $125(100)$ & $54(100)$ & 179(100) \\
\hline
\end{tabular}

Fonte: Banco de dados formado pelas respostas dos questionários, p=0,513.

Na Tabela 10 encontram-se a variável satisfação, e os diferentes fatores (questões) envolvendo a satisfação dos egressos. Decorrente dos achados emergentes referentes às necessidades intrínsecas (motivating factors) e extrínsecas (maintenance factors) dos egressos, realizou-se o Alpha de Cronbach, Tabela 10. Os valores encontrados nos clusters, ou seja, para os fatores extrínsecos foi de 0,82 , considerado de acordo com Cronbach e Shavelson (2004) e Freitas e Rodrigues (2005) uma consistência interna alta $(0,75<\alpha \leq 0,90)$, e para os fatores intrínsecos, o Alpha de Cronbach foi de 0,91 que, segundo os mesmos autores, representa uma consistência interna muito alta.

As questões foram relacionadas à teoria de Herzberg: a Two-Factor Theory (HERZBERG et al., 1957; HERZBERG; MAUSNER; SNYDERMAN, 1959; HERZBERG, 1971; HERZBERG; MAUSER; SNYDERMAN, 2005). De acordo com essa teoria, a satisfação com o trabalho, com o salário e com o crescimento profissional correspondem a fatores extrínsecos (maintenance factors). Já a satisfação com as competências desenvolvidas, com os conhecimentos adquiridos, com as práticas, métodos e teorias desenvolvidas durante o curso, bem como com as atividades extraclasses oferecidas aos estudantes correspondem a fatores intrínsecos, pois, de acordo com os autores supracitados, tais aspectos contemplam o desenvolvimento, o progresso e a realização da pessoa. 
Tabela 10 - Contribuição dos fatores componentes no teste Alpha de Cronbach

\begin{tabular}{|c|c|c|c|}
\hline \multirow[b]{3}{*}{ Variáveis } & \multirow[t]{3}{*}{ Indicadores de satisfação } & \multicolumn{2}{|c|}{ Dimensão teórica } \\
\hline & & \multicolumn{2}{|c|}{ Contribuição de cada fator componente no teste } \\
\hline & & $\begin{array}{l}\text { Fatores intrínsecos }{ }^{\star} \\
\text { (motivating factors) }\end{array}$ & $\begin{array}{l}\text { Fatores extrínsecos }{ }^{\star \star} \\
\text { (maintenance factors) }\end{array}$ \\
\hline & Com o trabalho & 0,5187 & 0,6836 \\
\hline & Com o salário & 0,4603 & 0,7244 \\
\hline & Com crescimento profissional & 0,4566 & 0,7237 \\
\hline & Com a graduação & 0,6422 & 0,0544 \\
\hline \multirow[t]{6}{*}{ Satisfação } & $\begin{array}{l}\text { Com as competências } \\
\text { desenvolvidas }\end{array}$ & 0,7400 & $-0,0064$ \\
\hline & $\begin{array}{l}\text { Com os conhecimentos } \\
\text { adquiridos }\end{array}$ & 0,8173 & $-0,1867$ \\
\hline & Com as práticas desenvolvidas & 0,8278 & $-0,2670$ \\
\hline & $\begin{array}{l}\text { Com os métodos } \\
\text { desenvolvidos }\end{array}$ & 0,8627 & $-0,3135$ \\
\hline & Com as teorias desenvolvidas & 0,8180 & $-0,3046$ \\
\hline & Com atividades extraclasses & 0,7859 & $-0,1978$ \\
\hline Consistência Interna (Alpha) & & 0,91 & 0,82 \\
\hline
\end{tabular}

Fonte: Banco de dados formado pelas respostas dos questionários. ${ }^{*} \mathrm{p}=0,83, * * \mathrm{p}=0,53$

O T-test também foi realizado após a criação das escalas para os fatores extrínsecos e intrínsecos. Em ambos não houve diferença estatisticamente significativa entre ter sido bolsista ProUni ou não, com médias respectivamente de 3,84 e 3,83 para os fatores extrínsecos, com p=0,53, e para os intrínsecos de 3,88 para ProUni e 3,75 para não bolsistas, com $\mathrm{p}=0,83$. Isso significa que não há uma diferença entre as respostas dos dois grupos de egressos, ou seja, o grau de satisfação entre os egressos tem o mesmo efeito. Ter sido ProUni ou não ProUni não evidencia ser mais ou menos satisfeito com fatores apresentados acerca de satisfação.

A Tabela 11 apresenta a média de satisfação dos egressos com o seu trabalho atual, com o salário, com o crescimento profissional, com a formação, com as competências desenvolvidas, com os conhecimentos adquiridos no curso, com as práticas, métodos e teorias desenvolvidos pelos docentes durante o curso e com as atividades extracurriculares oferecidas pela IES na qual se graduaram. Também é apresentada nessa Tabela a diferença entre as médias, bem como o nível de significância da diferença entre ser ProUni ou não ProUni pelo T-test.

Observa-se, na Tabela 11, que a média de satisfação dos egressos ProUni não é maior que a de seus colegas somente em um caso, a satisfação com o crescimento profissional. Nos 
demais casos, a satisfação dos prounistas apresentou-se maior. Em ambos os grupos a maior média de satisfação está para a satisfação com a graduação, com 4,20 para os não ProUni e 4,26 entre os que foram ProUni, seguido pela satisfação com o trabalho com 4,18 para o não ProUni e 4,24 para os que foram ProUni. Denota-se aqui que, para ambos os grupos, a conquista da formação e do trabalho têm um alto grau de satisfação (próximo ao valor máximo 5), evidenciando a realização de dois fatores relacionados respectivamente a necessidades intrínsecas e extrínsecas ao ser humano (HERZBERG et al., 1957; HERZBERG; MAUSNER; SNYDERMAN, 1959; HERZBERG, 1971; HERZBERG; MAUSER; SNYDERMAN, 2005).

Tabela 11 - Média de satisfação dos egressos não ProUni e ProUni que estavam trabalhando

\begin{tabular}{llcccc}
\hline & \multicolumn{1}{c}{ Fatores } & Não ProUni & ProUni & & \multicolumn{2}{c}{$\begin{array}{c}\text { Significância da } \\
\text { diferença } \\
\text { Variável }\end{array}$} & Média & Média & Diferença & p \\
\hline & Trabalho & 4,18 & 4,24 & $-0,06$ & 0,339 \\
& Salário & 3,53 & 3,57 & $-0,04$ & 0,407 \\
& Crescimento profissional & 3,78 & 3,70 & 0,08 & 0,362 \\
& Fatores extrínsecos & 3,83 & 3,84 & $-0,01$ & 0,468 \\
& Graduação & 4,20 & 4,26 & $-0,06$ & 0,668 \\
& Competências & 3,86 & 4,06 & $-0,19$ & 0,109 \\
& desenvolvidas & & & & 0,179 \\
& Conhecimentos adquiridos & 3,73 & 3,89 & $-0,16$ & 0,138 \\
& $\begin{array}{l}\text { Práticas desenvolvidas pelos } \\
\text { docentes }\end{array}$ & 3,74 & 3,93 & $-0,18$ & 0,201 \\
& Métodos desenvolvidos & 3,62 & 3,76 & $-0,14$ & 0,379 \\
& $\begin{array}{l}\text { pelos docentes } \\
\text { Teorias desenvolvidas pelos }\end{array}$ & 3,78 & 3,83 & $-0,05$ & 0,296 \\
& $\begin{array}{l}\text { docentes } \\
\text { Atividades extraclasses }\end{array}$ & 3,31 & 3,43 & $-0,12$ & 0,173 \\
\hline
\end{tabular}

Fonte: Banco de dados formado pelas respostas dos questionários.

As médias para os não ProUni e ProUni referente a fatores extrínsecos foi de 3,83 e 3,84 respectivamente, resultando em uma diferença de $-0,01$. A diferença entre a média dos grupos para fatores intrínsecos foi de $-0,13$, apontando a média de 3,75 de satisfação entre os não bolsistas, menor do que a de seus pares, que foi de 3,88. Tais achados caracterizam-se como emergentes dentro deste estudo, visto que eles não haviam sido traçados à priori.

A menor média de satisfação apresentada corresponde a atividades extraclasse oferecidas pela IES para ambos os grupos, com 3,31 para os que não foram ProUni e 3,43 entre os que foram. A segunda menor média corresponde à satisfação com o salário, em ambos os grupos de egressos. Não houve diferença estatisticamente significante entre os 
valores da variável satisfação e ser egresso ProUni ou não ProUni em nenhum dos fatores correspondentes a diferentes perspectivas de satisfação.

\section{Conclusões}

Ser a primeira geração a graduar-se, a ter a chance da realização de uma faculdade, constitui-se aspecto de suma importância no campo da mobilidade social. Em outras palavras, é uma nova geração que tem acesso ao conhecimento, a novos saberes, culturas e relações com novas e diferentes formas de ver, pensar, agir e enfrentar o mundo. É um desencadear de mudanças na vida e no contexto no qual estão inseridos esses graduados. Há a construção de um capital cultural que seus antecessores não tiveram oportunidade de fazer, podendo refletir nas suas futuras gerações, proporcionando melhores perspectivas de vida na sociedade, e em extensão maior, desenvolvimento social e econômico ao país.

Isso não é aqui entendido como uma premissa simplista voltada às questões sociais, pois se sabe que a complexidade do desenvolvimento de uma nação vai além de uma formação universitária. Entretanto, sabe-se que a Educação Superior tem papel relevante no desenvolvimento cognitivo, profissional e econômico na vida de uma pessoa, e por extensão, na sociedade. Sendo assim, o que se quer apontar aqui é que o ProUni não tem somente colaborado para o acesso de um novo perfil de estudantes à universidade, mas também de um novo perfil de graduados nos núcleos familiares, na comunidade e em um contexto social maior. Isto é confirmado pela significância estatística encontrada no que diz respeito à primeira geração de graduados e ter sido ProUni ou não.

No contínuo da análise, observa-se que a satisfação com a realização da faculdade mostra-se relevante nos dois grupos de participantes da pesquisa. Ambos os grupos dão evidências de que a formação em nível superior está sendo o início de um novo caminho a ser trilhado em suas vidas. Junto à satisfação com o curso realizado está a continuidade na realização dos estudos, quer sejam estes na área de formação ou não, ou até mesmo com outra graduação.

A não significância estatística encontrada entre a realização do mesmo curso, a realização de novos cursos e ter sido ProUni ou não, evidencia que o ProUni coloca seus graduados no mesmo patamar de satisfação que seus colegas não ProUni.

Isso é congruente ao indicado pela maioria no que concerne a ter aumento salarial após a graduação, bem como o trabalho estar ou não relacionado com a graduação. Os resultados encontrados apontam para uma igualdade no que compete à associação entre formação versus 
trabalho e a remuneração conquistada pelos egressos, ou seja, ambos os grupos de participantes nesta pesquisa estão no mesmo grau de conquistas no mercado de trabalho. A não significância estatística encontrada comprova isso. Em outras palavras, o ProUni, além do acesso à Educação Superior, está dando condições a seus egressos de competirem igualitariamente no mercado de trabalho, evidenciando que, de uma forma geral, os coloca no mesmo âmbito social. Destaca-se assim que a formação universitária pode sim contribuir para melhorias na vida das pessoas e para o desenvolvimento da sociedade e do país.

Também não houve significância estatística entre ser ProUni ou não e a quantidade de horas semanais trabalhadas, a categoria administrativa, o vínculo empregatício e o salário atual. Evidencia-se assim a relevância do ProUni enquanto Programa de Ação Afirmativa, pois está cumprindo com seu objetivo primeiro de proporcionar o acesso a Educação Superior, e em extensão, a igualdade de oportunidades às pessoas no contínuo social. Isto implica dizer que os egressos prounistas estão em condições de competir na conquista de novas e melhores perspectivas de vida.

A contribuição de cada fator de satisfação, delineado à dimensão teórica fator intrínseco e extrínseco, evidencia que há uma consistência interna alta (Alpha de Cronbach igual a 0,91 e 0,82 , respectivamente) em ambas as dimensões, o que denota que o instrumento construído responde aos fatores intrínsecos e extrínsecos emergidos na análise dos dados aqui realizada. Em outras palavras, o conjunto de questões é apropriado ao objetivo deste estudo.

Com relação à média de satisfação dos egressos ProUni e não ProUni com os fatores intrínsecos e extrínsecos, observa-se que não houve significância na diferença entre as médias dos que foram ProUni e seus colegas não ProUni, embora os prounistas mostrem estar um pouco mais satisfeitos que seus colegas em quase todos os fatores. Tais dados confirmam os achados já apresentados anteriormente neste artigo, de que ambos os grupos de egressos estão no mesmo patamar de satisfação acerca das variáveis aqui investigadas. Sendo assim, a análise apresentada neste artigo respondeu às três questões de pesquisa delineadas: Qual a situação dos egressos ProUni e não ProUni no mercado de trabalho e como ela difere entre os dois grupos de graduados? Em que medida o ProUni motiva o egresso prounista a continuar estudando? Qual a satisfação dos egressos ProUni e não ProUni com aspectos relacionados à sua formação e ao seu trabalho e como ela difere entre os dois grupos de graduados?

Tais achados instigam a reflexão da importância de programas como o ProUni. Entretanto, não seremos ingênuos em pensar que ele é a solução da problemática do acesso ou da permanência na universidade, ou então, responsável pela solução da iniquidade de acesso existente nesse nível de ensino. Podemos porém afirmar que ele proporciona o acesso à 
Educação Superior a pessoas provenientes de grupos subrepresentados (alunos egressos dos ensino público, afrodescendentes, indígenas, portadores de deficiência física e outros), bem como melhorias na vida de seus egressos. Isto é notório, visto que este estudo não se deteve somente em estudar egressos que foram bolsista de tal Programa, mas também os que não foram, dando assim uma visão do que de fato ocorre com os egressos da Educação Superior de uma forma mais abrangente e completa. Deste modo, este estudo evidencia a necessidade de estudos maiores, envolvendo egressos de diferentes Instituições de Educação Superior e de todas as Regiões do Brasil. Somente estudos com tal magnitude podem comprovar ou não os efeitos, ou seja, os impactos que o Programa Universidade para Todos vem desencadeando no contexto brasileiro. Estudos pequenos, como este, são sinalizadores de um cenário que merece atenção e acompanhamento.

O ProUni, como qualquer outro programa de ação afirmativa, necessita de acompanhamento de modo a ser melhorado no contínuo de sua existência, apontando e comprovando as mudanças ou não por ele geradas na sociedade como um todo. $\mathrm{O}$ monitoramento dos resultados do Programa é fundamental para identificar se ele está cumprindo com seu objetivo fundamental, e se agrega outros benefícios à sociedade, como forma de alcance da igualdade entre as oportunidades de desenvolvimento do indivíduo na sociedade. Sendo assim, dada a relevância que o Programa vem mostrando ter, e diante do estudo aqui apresentado, conjectura-se a necessidade de pesquisas envolvendo egressos da Educação Superior, quer tenham sido bolsistas ou não, em âmbito nacional. Para tanto, é fundamental o apoio do Ministério da Educação para a implementação e desenvolvimento de pesquisas desse porte e natureza.

\section{Referências}

ACOCK, Alan C. A. Gentle introduction to stata. Fourth edition. TX: Stata Press, 2014. ALMEIDA, Sergio Campos de. $O$ avanço da privatização na educação brasileira: o PROUNI como uma nova estratégia para a transferência de recursos públicos para o setor privado. 2006. 123 f. Dissertação (Mestrado em Educação) - Universidade Federal Fluminense, Niterói, 2006.

ANDRIOLA, Wagner Bandeira. Estudo de egressos de cursos de graduação: subsídios para a autoavaliação e o planejamento institucionais. Educ. rev., Belo Horizonte, n. 54, p. 203-220, 2014.

ASTI VERA, Arnaldo. Metodologia da pesquisa científica. 5. ed. Porto Alegre: Globo, 1979.

BENITEZ, Elizabeth Aparecida de Souza Marques. A expansão dos cursos de graduação em enfermagem no Brasil no período de 1991 - 2005. 2007. 147 f. Dissertação (Mestrado em Educação) - Universidade Católica de Petrópolis, Petrópolis, 2007. 
BÓS, Ângelo José Gonçalves. Epi Info® sem mistérios: um manual prático [recurso eletrônico]. Porto Alegre: EDIPUCRS, 2012. Disponível em:

<ebooks.pucrs.br/edipucrs/epiinfo.pdf>. Acesso em: 6 jan. 2016.

BOURDIEU, Pierre; PASSERON, Jean-Claude. Les héritiers: les étudiants et la culture. Paris: Les Éditions de Minuit, 1964.

BRASIL. Decreto nº 8.659 de 5 de abril de 1911. Aprova a lei Orgânica do Ensino Superior e do Fundamental na República. Diário Oficial da União, Rio de Janeiro, 05 de abril de 1911. Disponível em: <http://www6.senado.gov.br/legislacao/ListaPublicacoes.action?id=58698 htm>. Acesso em: 12 ago. 2009.

BRASIL. Lei $\mathbf{n}^{\mathbf{0}}$ 11.096, de 13 de janeiro de 2005. Institui o Programa Universidade para Todos PROUNI, 2005. Presidência da República. Diário Oficial da União, Brasília, DF. Disponível em: <http://www.planalto.gov.br/ccivil_03/_Ato2004-2006/2005/LEI/L11096.htm>. Acesso em: 6 jan. 2016.

BORGHI, Idalina Souza Mascarenhas. Uma margem outra: itinerâncias de jovens das classes populares na Educação Superior. 2013. 253f. Tese (Doutorado em Educação) Universidade Federal da Bahia, Salvador, 2013.

BOVÉRIO, Maria Aparecida. ProUni: estudo multicasos com bolsistas beneficiários (estudantes e egressos) de sete instituições de ensino superior do interior do Estado de São Paulo. 2014. 471f. Tese (Doutorado em Educação Escolar) - Universidade Estadual Paulista Júlio de Mesquita Filho, Araraquara, 2014.

CARVALHO, Cristina Helena Almeida. A política pública para a educação superior no Brasil (1995-2008): ruptura e/ou continuidade? 2011. 465f. Tese (Doutorado em Ciências Econômicas) - Universidade Estadual de Campinas, Campinas, 2011.

CASHMORE, Ellis et al. Dicionário das relações étnicas e raciais. São Paulo: Summus, 2000.

COSTA, Fabiana Souza. O ProUni e seus egressos: uma articulação entre educação, trabalho e juventude. 2012. 201f. Tese (Doutorado em Educação: Currículo) - Pontifícia Universidade Católica de São Paulo, São Paulo, 2012.

COELHO, Fábio da Penha. A aprendizagem dos professores de Educação Física na fase inicial da docência: conhecimentos e práticas. 2011. 112f. Dissertação (Mestrado em Educação) - Universidade Federal de Mato Grosso, 2011.

COSTA, Fabiana Souza. O ProUni e seus egressos: uma articulação entre educação, trabalho e juventude. 2012. 201f. Tese (Doutorado em Educação: Currículo) - Pontifícia Universidade Católica de São Paulo, São Paulo, 2012.

CHOY, Susan P.; HORN, Laura J.; NUÑEZ, Anne-Marie; CHEN, Xianglei. Transition to college: what helps at-risk students and students whose parents did not attend college. New Directions for Institutional Research, Medford, v. 27, n. 3, p. 45-63, 2000.

CRONBACH, Lee J.; SHAVELSON, Richard J. My Current Thoughts on Coefficient Alpha and successor procedures. Educational and Psychological Measurement, California, v. 64 n. 3, p. 391-418, 2004.

DIEHL, Astor Antonio. Pesquisa em ciências sociais aplicadas: métodos e técnicas. São Paulo: Prentice, Hall, 2004. 
EWELL, Peter T. Establishing a Campus-Based Assessment Program. In.: HALPERN, D. F. (Ed.). Student outcomes assessment: what institutions stand to gain. New directions in Higher Education. San Francisco: Jossey-Bass, 1986.

EWELL, Peter T. Alumni studies as instruments of Public Policy: The U.S. Experience. New Directions for Institutional Research, Medford, n. 126, Summer, 2005.

FELDMAN, Márcia Regina dos Santos. Histórias que se cruzam na significação social dada ao Programa Universidade para Todos. 2010. 299f. Dissertação (Mestrado em Educação) - Universidade Nove de Julho, São Paulo, 2010.

FELICETTI, Vera Lucia. Comprometimento do estudante: um elo entre aprendizagem e inclusão social na qualidade da educação superior. 2011. 298f. Tese (Doutorado em Educação) - Pontifícia Universidade do Rio Grande do Sul, Porto Alegre, 2011.

FELICETTI, Vera Lucia. Graduados ProUni: um estudo comparativo entre licenciados e não licenciados. Estudos em Avaliação Educacional, São Paulo, v. 23, n. 53, p. 280-301, 2012.

FELICETTI, Vera Lucia. Licenciados ProUni: dificuldades no percurso acadêmico e resultados da formação. Revista Ibero-americana de Educación, Madrid, n. 64, v. 1, p. 2$10,2014 a$.

FELICETTI, Vera Lucia. Comprometimento do aluno ProUni: acesso, persistência e formação acadêmica. Revista Brasileira de Estudos Pedagógicos, Brasília, n. 95, v. 241, p. 526-543, 2014b.

FELICETTI, Vera Lucia; MOROSINI, Marília Costa. Equidade e iniquidade no ensino superior: uma reflexão. Ensaio: Avaliação e Políticas Públicas em Educação, Rio de Janeiro, v. 17, n. 62, p. 9-24, jan./mar. 2009.

FERNANDES, Glaucia Braga Ladeira. Universidade e inserção profissional: um estudo de egressos das Licenciaturas da Faculdade de Formação de Professores da UERJ. 2011. 157f. Dissertação (Mestrado em Educação - Processos Formativos e Desigualdades Sociais) Universidade do Estado do Rio de Janeiro, Rio de Janeiro, 2011.

GERALDO, Aparecida das Graças. Os egressos do ProUni e Cotas no mercado de trabalho: uma inclusão possível? 2010. 216f. Dissertação (Mestrado em Educação, Arte e História da Cultura) - Faculdade de Educação, Universidade Presbiteriana Mackenzie, São Paulo, 2010.

GONÇALVEZ DE SOUSA, Ana Maria. Financiamento público estudantil do ensino superior: uma análise comparativa dos casos do Brasil e de Portugal. 2008. 254f. Tese (Doutorado em Educação) - Universidade Federal de Goiás, Goiânia, 2008.

HERZBERG, Frederick. Work and the nature of man. New York: World Publishing, 1971. HERZBERG, Frederick; MAUSNER, Bernard; SNYDERMAN, Barbara B. The motivation to work. New York: John Wiley, 1959.

HERZBERG, Frederick; MAUSNER, Bernard; SNYDERMAN, Barbara Bloch. The motivation to work. 2. ed. New Jersey: Transaction Publishers, 2005.

HERZBERG, Frederick; MAUSNER, Bernard; PETERSON, Richard O.; CAPWELL, Dora. Job attitudes: review of research and opinion. Pittsburgh, PA: Psychological Service of Pittsburgh, 1957.

ISHITANI, Terry T. Studying attrition and degree completion behavior among firstgeneration college students in the United States. Journal of Higher Education, London, v. 77, n. 5, p. 861-885, 2006. 
KRAMES, Ilisabet Pradi. Na trilha do PROUNI: implantação, acompanhamento e perspectivas em uma instituição de ensino superior de Santa Catarina. 2010. 130f. Tese (Doutorado em Educação) - Pontifícia Universidade Católica de São Paulo, São Paulo, 2010.

LIMA, Francisco José Sousa. Identidade étnico-racial no contexto das políticas de ação afirmativa. 2007. 130f. Dissertação (Mestrado em Educação) - Escola Superior de Teologia, São Leopoldo, 2007.

MARCONI, Marina de Andrade; LAKATOS, Eva Maria. Fundamentos de metodologia científica. São Paulo: Atlas, 2003.

MARINELLI, Célia Regina G. Programa Universidade para Todos - Aspectos da cidadania fragmentada. 2010. 233f. Tese (Doutorado em Educação) - Universidade Metodista de Piracicaba, Piracicaba, 2010.

MELLO, Cleverson Molinari. Programa universidade para todos - PROUNI: acesso ao Ensino Superior e qualificação. Para quê? 2007. 143f. Dissertação (Mestrado em Educação) Universidade Tuiuti do Paraná, Curitiba, 2007.

MONGIM, Andrea Bayerl. Título universitário e prestígio social: percursos sociais de estudantes beneficiários do ProUni. 2010. 176f. Tese (Doutorado em Antropologia) Universidade Federal Fluminense, Rio de Janeiro, 2010.

OLIVEIRA, Alcivam Paulo. A relação entre o Público e o Privado na Educação superior no Brasil e o programa Universidade para Todos (PROUNI): ambiguidades e contradições. 2007. 304f. Tese (Doutorado em Educação) - Universidade Federal de Pernambuco, Recife, 2007.

OLIVEIRA, Cristiane Pereira Melo de. Programa Universidade para Todos: a percepção dos estudantes de uma universidade privada de são Paulo. 2012. 186f. Dissertação (Mestrado em Educação) - Universidade Cidade de São Paulo, São Paulo, 2012.

PASCARELLA, Ernest T.; TERENZINI, Patrick T. How college affects students: findings and insights from twenty years of research. São Francisco: Jossey-Bass, 1991. v. 1.

PEREIRA FILHO, Ednaldo da Silva. Perfil de jovens universitários bolsistas do ProUni: um estudo de caso na Unisinos. 2011. 131f. Tese (Doutorado em Ciências Sociais) Universidade do Vale do Rio dos Sinos, Porto Alegre, 2011.

PITA, T. J. Destino social de alguns egressos do Curso de Pedagogia de uma instituição de ensino superior privada com baixa avaliação no Ministério da Educação (2007-2011). 2011. 83f. Dissertação (Mestrado em Educação: História, Política, Sociedade) - Pontifícia Universidade Católica de São Paulo, São Paulo, 2011.

REIS, Ana Maria. Democratização do acesso e políticas afirmativas na Educação Superior. 137f. Dissertação (Mestrado em Educação) - Universidade de Sorocaba, Sorocaba, 2008.

ROCHA, Antonia Rozimar Machado. Programa universidade para todos - ProUni e a pseudo-democratização na contra-reforma da educação superior no Brasil. 2009. 217f. Tese (Doutorado em Educação) - Universidade Federal do Ceará, Fortaleza, 2009.

ROCHA, Maria Aparecida Marques da. Processo de inclusão ilusória: a condição do jovem bolsista universitário. 2008. 266f. Tese (Dourado em Serviço Social) - Pontifícia Universidade Católica do Rio Grande do Sul, Porto Alegre, 2008.

RODRIGUEZ, Sandria. What helps some first-generation students succeed? About Campus, Medford, v. 8, n. 4, p. 17-22, 2003. 
RODRIGUES, Aguiar Correia. "Passar é fácil, continuar é que é difícil..." 2008. 176f. Dissertação (Mestrado em Serviço Social) - Pontifícia Universidade Católica do Rio de Janeiro, Rio de Janeiro, 2008.

SILVA, Fernando César Marra. Políticas públicas de inclusão social e iniciativas de acessibilidade no Ensino Superior particular do triângulo mineiro: uma discussão das tendências na ótica de formadores de opinião. 2006. 139f. Dissertação (Mestrado em Educação) - Universidade São Marcos, Belo Horizonte, 2006.

SILVA, Eduardo Henrique de Oliveira. Financiamento de bolsas de estudo para o ensino superior: O Programa Universidade para Todos (PROUNI), em Mato Grosso do Sul, no período de 2005 a 2010. 2011. 161f. Dissertação (Mestrado em Educação) - Universidade Federal do Mato Grosso do Sul, Campo Grande, 2011.

SILVA, Daniela. O curso de Licenciatura em Matemática da PUC/SP e a trajetória educacional de seus egressos (2005-2010). 2012. 107f. Dissertação (Mestrado em Educação Matemática) - Pontifícia Universidade Católica de São Paulo, São Paulo, 2012.

SINAES. Da concepção à regulamentação. Brasília: INEP/MEC, 2009.

SISPROUNI. Sisprouni de 06/01/2015 Bolsistas ProUni 2005-2\%/2014. Sistema informatizado do PROUNI. 2015. Disponível em:

〈http://prouniportal.mec.gov.br/images/pdf/Representacoes_graficas/bolsistas_por_sexo.pdf> . Acesso em: 18 jul. 2015.

SOUZA, Luiz Eduardo Rodrigues de Almeida. O ProUni como política pública de Ação Afirmativa: uma análise do impacto sociocultural na trajetória de egressos, oriundos das camadas populares, do ProUni da PUC-MG. 2011. 113f. Dissertação (Mestrado em Educação) - Pontifícia Universidade Católica de Minas Gerais, Belo Horizonte, 2011.

TERENZINI, Patrick T. et al. First-generation college students: Characteristics, experiences, and cognitive development. Research in Higher Education, Chennai, v. 37, n. 1, p. 1-22, 1996.

ULIANA, Edna Regina. Formação inicial e áreas de atuação profissional de egressos do curso de Licenciatura Plena em Ciências Biológicas da Universidade Federal de Mato Grosso do período de 2004-2009. 2011. 165f. Mato Grosso. Dissertação (Mestrado em Educação) - Universidade Federal de Mato Grosso, Cuiabá, 2011.

Vera Lucia Felicetti - Universidade La Salle Canoas | RS | Brasil. Contato: verafelicetti@ig.com.br

Alberto F. Cabrera - Universidade de Maryland College Park|Estados Unidos. Contato: cabrera@umd.edu 